\title{
Challenges of bank senior executives at midlife: a phenomenological case study
}

\begin{abstract}
Midlife is commonly associated with crisis caused by negative experiences during the middle period of life. Perceived crisis results middle-aged individuals become vulnerable and stressed. There are reports at midlife stage showing a decrease in happiness, life satisfaction, and worth whileness, while an increase in suicidal rate. Given these alarming facts, the researcher aims to revisit the mental health of midlifers by verifying the trigger of the perceived crisis during the midlife stage through phenomenological study which can be used as a basis for an intervention program. This aims to reduce the risk of cognitive decline and the likelihood of developing an illness as well as to promote mental well-being. The researcher explored the challenges encountered by 41 Senior Executives' (with rank of Senior Manager to Senior Vice President) through focus group discussion and interview. This is supported by observation of the current scenario, review of related literatures and theories. These Senior Executives come from one financial institution in the Philippines whose age ranges from 40 to 55 years. With the gathered data, descriptive thematic analysis and repertory grid were used to determine patterns of their challenges. From these methods, themes were formulated based on the theories of Levinson, Jung, and Erikson and analysis resulted from the following findings: (1) Due to the emerging future, Senior Executives become conscious on their apparent aging and possible health problems, (2) More than half of the Senior Executives are self-deliberating and confused, (3) A number of female Senior Executives have been found to be more concerned about their relationship towards family and friends than males, and (4) Male and female Senior Executives have similar patterns of challenges such as Impermanence, Individuality and Interrelation.
\end{abstract}

Volume 6 Issue | - 202|

Mary Jane MValero, Maria Claudette Agnes
The Graduate School, University of Santo Tomas Manila,

Philippines

Correspondence: Mary Jane MValero, The Graduate School, University of Santo Tomas Manila, Philippines,

Email maryjanevalero@yahoo.com

Received: January 01, 202I | Published: January 12, 202 |

Keywords: midlife, crisis, senior executives, stress, depression

\section{Introduction}

Middle life borders are still fuzzy and have no clear demarcation; dictionaries simply describe it as the period between youth and old age. ${ }^{1}$ It is a phase of life a midlifer (middle-aged individual) perceives as a period of disappointment, anxiety, and crisis; it could also be a time for them to explore their inner selves and restructure their outer lives. ${ }^{2}$ Although this period is accompanied with serious unhappiness, it can also be viewed as a time for remarkable growth. ${ }^{3}$ However, individuals perceive crisis at this stage because they tend to question the purpose of their lives which make them aware of their repressed wants, and compare their current lives to their dreams and goals. ${ }^{4}$ The realization of unfulfilled wants and wishes create confusion because they are unsure whether they will pursue them or not. ${ }^{5,6}$ These experiences, changes, and realizations are the reasons why they associate midlife with crisis, confusion, and disappointment. With this perceived crisis, midlifers become vulnerable and stressed. ${ }^{7}$ At this point, if stress is not properly managed, it could become chronic and could lead to anxiety, depression, ${ }^{8}$ fatigue and other health problems such as headaches, upset stomach, high blood pressure, chest pain, sleeping problem, ${ }^{9}$ heart problems, diabetes, skin disease, asthma, and arthritis. ${ }^{10}$ There is also a strong evidence that there is indeed a U-shape or U-curve in the life cycle of humans, ${ }^{11,12}$ a decrease of happiness and well-being during middle age in the human life course. Suicidal rate is also rampant in the United States from 1999-2010 where they found out that there is a significant increase of $28.4 \%$ among the 35-64-year-old. ${ }^{13,14}$ The suicidal cases are caused by stress from economic challenges, dual caregiver responsibilities (children and aging parents), and health problems. While in 2016, people aged between 40-44 in the United Kingdom are found to have the highest prevalence of suicide. ${ }^{15}$ On the other hand, suicide cases are likely under-reported in the Philippines due to the non acceptance by the Catholic Church and associated stigma to the family ${ }^{16}$ though it was emphasized that there was an increase in the suicidal rate from 1974 to 2005 from 0.23 to 3.59 per 100,000 in males and 0.12 to 1.09 per 100,000 in females. Males have similar suicidal rates among all age groups unlike with females which is only common to women, with an age of 15-24 years. Though these reports show low suicidal rate in the Philippines among midlifers, it is imperative to prevent its tendencies since there is no confirmation yet of actual statistics. This uncertainty opens the idea and the probability that there are individuals at midlife who are desperate for change and seeks some explanation to their agony.

\section{Literature review}

Renowned Psychologists such as Erik Erikson, Carl Jung, and Daniel Levinson provided a context to understand the phenomenon of midlife as experienced by individuals within this age group (Figure 1). As for Erikson, this period is associated with struggles with two opposing sides, which are generativity and stagnation, ${ }^{17}$ while Jung sees midlife as associated with crisis which is inevitable and universal in which individuals experience necessary and valuable changes. ${ }^{3}$ However, for Levinson this is just a transition and not a crisis. ${ }^{18}$ Nevertheless, out of all these points of view, they all fall under the same path of achieving a strong sense of autonomy, individuation, and self-acceptance. 


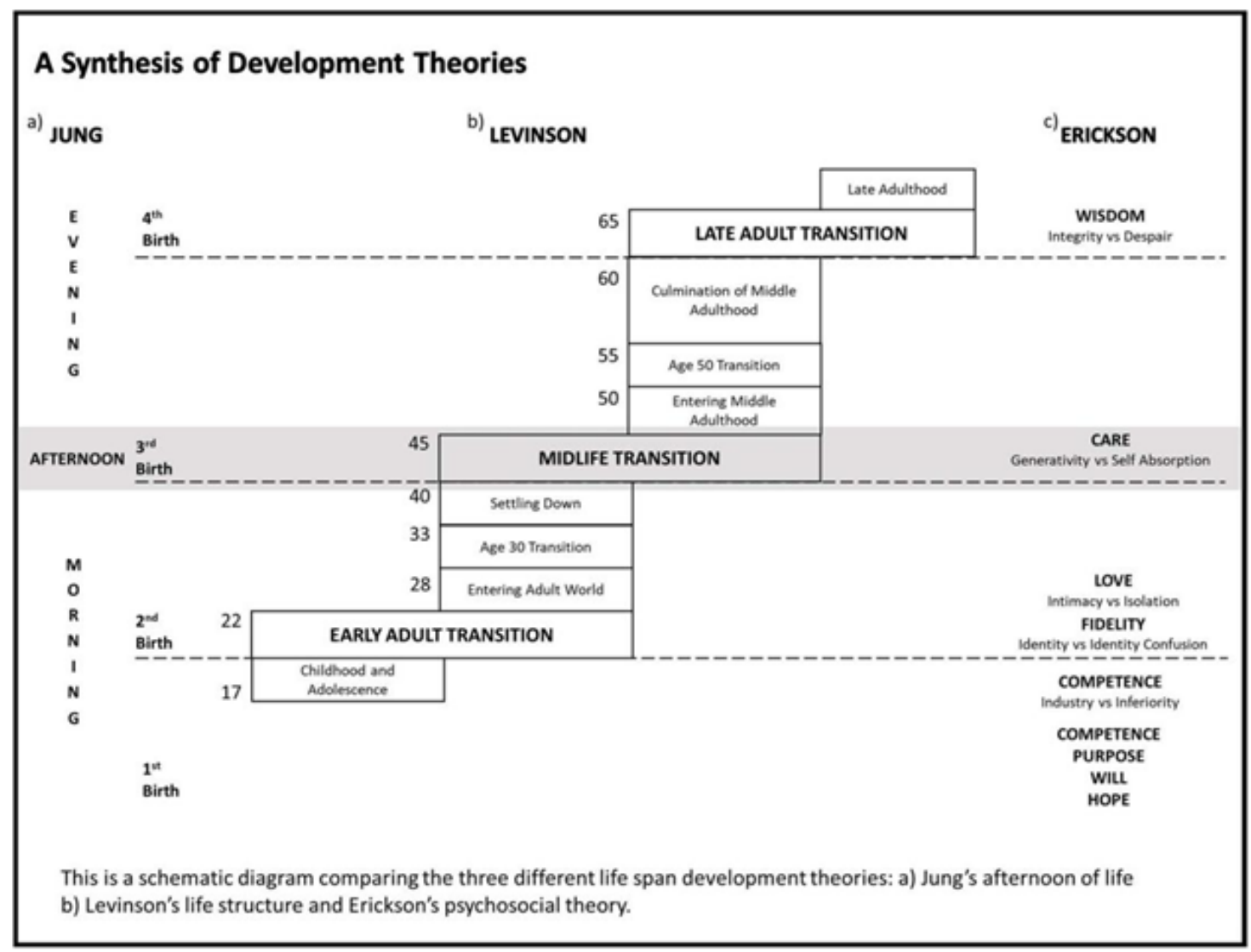

Figure I A synthesis of development theories.

Daniel Levinson's life structure theory creates a pattern or design of the person's life with a specific time frame. ${ }^{19}$ There are three major transitions in a man's life to pivot or turn drastically based on personal choices. These are the early adult transition, midlife transition, and late adult transition. Middle life stage is only one of the transitions in the life course, contradictory to apparent crisis. ${ }^{18}$ Crisis is just the effect of the radical changes caused by the three major developmental tasks at midlife which are:

1) They review, reappraise, and terminate their earlier adult period; 2) they create decisions on how to start and act their period of middle adulthood; and 3) they deal with the polarities that cause profound division in their lives. ${ }^{20}$ From Jungian perspective, he borrowed the concept of polarities to explain the continual struggle a midlifer experiences: young/old (for they try to find ways to be both young and old), destruction/creation (for they must compensate the destructive acts from the past thru helping the next generation and leaving a legacy for the future), masculinity/femininity (for they want to reconcile the masculine side of the female and feminine side of the males) and attachment/separation (for they must create balance between the engagement in the external world and separateness from it). ${ }^{21}$ With Jung's principle of enantiodromia and principle of polarities, these struggles are explained. If there is a superabundance of forces on one side, it will inevitably give way to its opposite. ${ }^{22}$ This means that, if one perceives that $\mathrm{s} / \mathrm{he}$ is getting old, the energy invested on that area will be shifted to another aspect of life such as wanting to look and feel young, acting and talking like a young person, and thinking that one is still capable of doing the things young people do. These people exhibit these behaviors in various forms such as adopting a more athletic style in dressing or going to the gym to workout. Otherwise, if this energy is not transmitted, it will flow to the unconscious ${ }^{3}$ and if not resolved, it will cause conflict within and will affect old age..$^{23}$

On the other hand, Carl Jung's midlife stage starts from the age of 35 to 40 in which major personality deviations occur. ${ }^{3}$ Jung uses the analogy of the sun to illustrate the human life cycle. Based on his idea, youth is like morning (first part of life), midlife (second part of life) corresponds to afternoon and old age (third part of life) is comparable to night. ${ }^{24}$ Per Jung, the major aim during midlife stage is individuation, the realization of oneself, acceptance of the innermost unique self, and integration of consciousness and unconsciousness aspect of the personality. ${ }^{22,25}$ In the process of individuation, the first half of life (morning/early adult transition) is spent engaging oneself with the world and finding place to establish career, marriage, and community to the point of suppressing parts of the self. The second half (afternoon/midlife transition) is about becoming one's true self, and re-evaluating abilities and dreams. ${ }^{23}$ The second half of life's main task is to achieve individuation or coming-to-be of the self. ${ }^{26}$ Jung significantly emphasized that morning and afternoon transitions have their own tasks, thus to carry the issues and aspects of the self that have not been addressed, or ignored from the first half of life to the second half would be neurotic and would bring impairment to the soul. ${ }^{23}$ This is the reason behind Jung's statement that individuals who are in middle life tends more likely to experience problems. ${ }^{27}$

Similar to what Jung proposes, Erik Erikson's psychosocial theory believes that individuals carry their unresolved issues from earlier to later stages of life, as he believes that human development is in a linear way and each stage is essential to pass through. ${ }^{28}$ Parallel to this, Erikson's epigenetic principle states that crisis occurs in each eight stages of psychosocial theory and failure to resolve it will lead 
to unhealthy personality and sense of self. ${ }^{29}$ Midlife is in the seventh stage of psychosocial theory in which an individual faces the reality of old age, the choosing between the polarities of either be a good example to the next generation or remaining stagnant. ${ }^{17}$ This is the stage in which an individual approach the end of life, thus $\mathrm{s} /$ he feels the need to leave behind a lasting legacy and be present in the next generation. Several avenues for generativity include raising children, becoming involved in community activities and organizations, ${ }^{29}$ production of work and creation of new things and ideas. ${ }^{17}$ According to Erikson, when an individual fails to manage developmental challenges, s/he would experience stagnation (e.g., lack of creativity and productivity) and emotional distress (i.e. depression or despair) that have an implication in an individual's understanding, adult development, health and well-being. ${ }^{30}$

All these developmental theories' goal is to achieve individuation or the fullness of life. Each theorist purports her/his own concepts and tasks on the midlife stage. However, if a midlifer fails to perform the task, s/he will experience internal conflict (Levinson), possess a neurotic personality (Jung), and stagnate in his development (Erikson). These only show that people who are in middle age are on the verge of reaching the crucial point in adult life in which critical decisions have to be made. ${ }^{31}$

As it is, midlife stage already brings crisis, stress, and the likelihood of suicide; what more if the individual is working as a senior corporate executive, which is considered as the seventh most stressful job. ${ }^{32}$ Stress is common among executives and managers who describe midlife as a turbulent and demanding phase of their life. ${ }^{33}$ It is clear that they are not exempted from experiencing midlife adjustments despite occupying/holding high positions having financial stability, and material possessions. Hence, the researcher deemed it necessary to study the responses of Senior Executives (with rank of Senior Manager to Senior Vice President) towards midlife.

\section{Purpose and limitation of the study}

The researcher wishes to collate, transcribe, and determine themes or patterns in their responses that need to be addressed. By knowing the midlife stage challenges, the researcher aims to develop an intervention program that aims to reduce the risk of decline of an individual's cognitive functioning, avoid any possible illnesses and promote mental well-being. This study is limited to only one financial institution where results cannot be used to generalize all midlifers. Instead, other researchers can use these data as basis for future research and analysis. The number of voluntary participants is another limitation. Since the respondents had executive positions, the schedule of some respondents would not allow the conduct of the sessions.

\section{Method}

\section{Participants}

Out of the 119 Senior Executives (with rank of Senior Manager to Senior Vice President), 102 voluntarily agreed to be part of the study. Even if there is an $86 \%$ positive participation, only 41 passed the set criteria. The study consisted of 23 males and 18 females. The selection of the participants was based on the idea that even if Senior Executives receive a higher salary, they still experience stress and turbulence at midlife. ${ }^{33}$ To assess if the selected participants experience crisis, their neuroticism level was measured using the MIDI Personality Scale ${ }^{31}$ because midlife crisis in the form of stagnation and death mortality can likely be measured if they possess high scores in the neuroticism scale. ${ }^{27}$ Stress, anxiety, and depression, on the other hand, were the manifestation of crisis which were evaluated using the Perceived Stress Scale (PSS) ${ }^{34}$ and the Hospital Anxiety and Depression Scale (HADS) ${ }^{35}$ respectively. Participants who scored above average in neuroticism, very high in stress, and borderline to abnormal case in anxiety and depression were included in the study. Parallel to the participant selection, the researcher anchored the problem analysis on the current scenario, ${ }^{36}$ reviewing the related literatures (RRL) in preparation for the focus group discussion (FGD) and conducting interviews which were the main methods of data gathering. Through this, the researcher was able to accumulate direct narratives from the selected Senior Executives and utilized descriptive thematic analysis and repertory grid to determine patterns or themes of their challenges.

\section{Materials}

This study used Midlife Development Inventory (MIDI) Personality Scale to measure neuroticism level, Perceived Stress Scale (PSS) for the stress level and Hospital Anxiety and Depression Scale (HADS) for anxiety and depression presence. These are the variables that are outwardly manifested by the individuals at the middle stage of life. ${ }^{2,8,9}$

\section{Midlife development inventory (MIDI) personality scale}

The Midlife Development Inventory (MIDI) Personality Scale was designed to measure personality patterns with respondents aged 25 to 75 . It consists of a six-personality-trait scale: agency, agreeableness, openness to experience, neuroticism, extraversion, and conscientiousness. ${ }^{31}$ These traits were measured using selfrating of 30 adjectives. Each item has a four-point scale: 1 - A Lot; 2 - Some; 3 A Little; $4-$ Not at All. The questionnaire is composed of 30 items and was pre-tested and validated arriving in the Cronbach alpha reliability estimates for each dimension; agency $(\alpha=.79)$, neuroticism $(\alpha=.74)$, extraversion $(\alpha=.78)$, conscientiousness $(\alpha=.58)$, agreeableness $(\alpha=$ $.80)$, and openness to experience $(\alpha=.77)$.

\section{Perceived stress scale (PSS)}

The Perceived Stress Scale (PSS) is a self-report measurement of stress. It is widely used to measure the degree of certain situations in one's life that is considered stressful. This research used Cohen and Williamson's version (1988) with 10-items due to the highest cronbach alpha of .78 against the others. Each item of PSS has direct queries about the participants' current levels of experienced stress with a five-point Likert scale: 0 - never; 1 - almost never; 2 - sometimes; 3 - fairly often and 4 - very often. The items were designed to know how unpredictable, uncontrollable, and overloaded the respondents find their lives. Based on the total scores, the level of perceived stress of the individual could be known.

\section{Hospital anxiety and depression scale (HADS)}

The Hospital Anxiety and Depression Scale (HADS) was established by Zigmond and Snaith ${ }^{35}$ of St. James University Hospital, Yorkshire, England. It is a questionnaire widely used to determine anxiety and depression disorder which comprises of 14-items, seven of which are related to anxiety and the other seven for depression. Each item is coded from 0 to 3 with different interpretations based on the question per item. Odd items are for anxiety while even items are for depression. The sum of the scores would determine the level of anxiety and depression. Even if HADS indicates 'hospital', it could also be used in non-psychiatric populations or community. ${ }^{37.38}$ Comparing it to other anxiety and depression assessments such as 
Depression Anxiety Stress Scale-21 (DASS-21) and Beck Depression and Anxiety Inventories (BDAI), HADS is simple, easy to score and with lesser number of items. It is not just a convenient tool but its psychometrics properties have also a Cronbach alpha of .78 for depression while .81 for anxiety scale. ${ }^{39}$

\section{Procedure}

This study started with the selection of participants, communicating and explaining to them the purpose of the study and assuring them of its confidentiality. Those who voluntarily agreed were asked to sign an informed consent and fill out a personal data sheet for participant profiling. Then, the MIDI, PSS, and HADS were administered to determine if they are currently going through any crisis. Upon passing the set criteria, the researcher scheduled the interview and focus group discussion (FGD). With current scenario, observation, review of related literature, and exploration of relevant theories, the guide questions were formulated which were used in the interview and discussion.

\section{Results}

Through the focus group discussions and interviews, the researcher was able to gather sufficient direct narratives from the selected Senior Executives. Using descriptive thematic analysis and repertory grid, the researcher was able to identify and determine themes or patterns from the collected data. ${ }^{40}$ Pattern of challenges that can be known as the triple 'I' - (1) Impermanence which is related to the concerns of a midlifer with mortality such as health and aging; (2) Individuality which is for most of the patterns that confirm a midlifer's self-deliberation and confusion during this stage of life; and (3) Interrelation which is pertaining to an individual's relationship towards work and colleague or with family and friends (Table 1).

Table I Themes and subthemes of the challenges experienced by the senior executives at midlife

\begin{tabular}{lll}
\hline Themes & \multicolumn{2}{l}{ Subthemes } \\
\hline Impermanence (TI) & I & Health Issues (TIa) \\
& 2 & Aging (TIb) \\
Individuality (T2) & I & Self-Deliberation (T2a) \\
& 2 & Confusion (T2b) \\
Interrelation (T3) & I & Family and Friends Concerns (T3a) \\
& 2 & Work/Colleagues Issues (T3b) \\
\hline
\end{tabular}

\section{Discussion}

\section{Impermanence}

Impermanence can be illustrated by the theory of Elliot Jacques on the acceptance of morality and Ernest Becker's denial of death which are both evident among middle-aged individuals. ${ }^{41}$ According to Jacques, facing mortality is one of the crucial developmental tasks during this stage whereas for Becker, denial of death serves as human's major motivator.

Impermanence pertains to health and aging issues raised by the Senior Executives. They expressively narrated their anxiety caused by their own illness or loved ones and by the passing of someone close to them. Crisis in midlife is commonly caused by life events such as death of a spouse or illness. ${ }^{42}$ Loss of someone close to midlifers triggers the thought of their issues towards mortality and how they are currently living. Here are sample verbal expressions:

"Being rolled into the operating room and having my uncle, aunt and grandparents pushed outside the door. Three years ago, I had my third operation in my achilles tendon which must be done every year in the hospital. You realize life is short. - Jeff

"I was overwhelmed when I found out that my spouse has cancerI felt that my life suddenly took a huge turn for the worst." - Kenneth Jenny

"The feeling of unhappiness during the death of my brother..." -

Other Senior Executives explicitly shared their observation towards their changing physical appearance and deteriorating stamina. The evidence of old age is revealing among midlifers which they cannot avoid such as (1) poor eyesight, body pains, and weak memory, (2) individuals of the same age begin to have illnesses such as heart problems, stroke, and other conditions and (3) parents, relatives, and friends are also aging, or are with illness or even dying, ${ }^{21}$ Here are the corresponding verbal expressions from the participants:

"Fear of deteriorating health and not having the ability to do the things that I could do easily when I was younger." - Gerald

"When I was about to turn 40, I was called obese. I decided not to be one and now I am working hard to hit my target weight and be healthy for the second half of my life." - Mary

"Maybe at most, I'm inconvenienced by hot flashes, which may indicate I'm rearing menopause. I wake up drenched in sweat in the middle of the night and even during some days in a month." - Karen

In Eric Erikson's psychosocial theory, middle age falls in the seventh stage in which midlifers face the reality of old age. ${ }^{17}$ As with Jung, this is the middle of the full cycle of the sun in which an individual is near an end. ${ }^{24}$ Mortality elicits crisis because it brings the awareness that midlifers will eventually die, that life is limited, which makes them think that their efforts will be pointless. ${ }^{43}$ According to Becker's theory, as mortality awareness increases, the more midlifers perceive that they need to defend themselves from the impending results. $^{41}$

\section{Individuality}

Meanwhile, individuality illustrates the coming to selfhood or selfdiscovery of the self which Carl Jung proposes to be happening during middle adulthood. ${ }^{22}$ This is the stage in which midlifers meditate, question, and assess life's purpose. Recognizing their repressed wants and comparing their current life with their dreams also occur. ${ }^{4}$ They become confused whether to pursue their unfulfilled wants and wishes or not. ${ }^{5,6}$ Even if they want to change the things that they acknowledge as wrong or unsatisfying (referred by Levinson as "breaking out"), they could no longer do it, ${ }^{4}$ because at this point, they do not just consider how they could benefit from it, but they also have to consider the people around them as they now have to balance multiple roles as son, husband, father, friend as well as a professional. If left unsolved, it would lead to stagnation and emotional distress. ${ }^{30}$ This is because they are stuck between the responsibilities of their parent's generation and their children's generation which is referred to be as sandwich generation. $^{18}$

This is the time when midlifers ask the what if's and realize that they have doubts and uncertainties, ${ }^{5,6}$ problems with regard to balancing 
family, friends, and work, ${ }^{30}$ unfulfilled dreams and unrecognized emotions which they have had for a long time. ${ }^{4}$ Senior Executives clearly depict these manifestations which reflected on their narratives:

"When I reached midlife, I wasn't able to achieve some of my goals; I started asking myself if I still wanted follow the same track." - Erika

"It is a point in life that people go through to examine themselves. Whatever roles they play in life at the moment, depends on their objectives. For some, it may be the start of something or a change, while for some, it is just a stage of realignment." - Steph

"You are not satisfied with what you have. You crave for something new. It is when you want to make some changes in your life. Sometimes you want to do something crazy." - Michelle

"When I thought of this, I feel sad and I realized my parents are not getting any younger, and they too will also leave me in the future." - Edward

"Being more sensitive with my feelings, specifically towards handling my emotions during work time." - Richard

\section{Interrelation}

On the other hand, Interrelation refers to the individual's relationship status towards family, friends, and work or colleagues. ${ }^{44}$ Relationship with various others is the primary component of life structure. ${ }^{19}$ Significant relationship involves an investment from the self and from the significant others. This relationship or social support creates the perception and the actuality that the individual is cared for which could be in a form of family, friends, and colleagues. Studies show that social support is associated with the manifestation of mental illness such as reducing the risk of an onset major depression and anxiety disorders. ${ }^{45}$ Furthermore, low social support is linked to an elevated stress hormone activity in systematic hypertension. ${ }^{46}$ Other studies, show that harmonious relationship generates affectivity, a chief motivator of human actions. ${ }^{47}$ This is the possible reason why whenever there is a misunderstanding among midlifers and their support group, it causes an inexplicable sadness. Here are some of the narratives of the Senior Executives presenting their issues:

"When my wife and I separated in which our marriage unfortunately ended up in annulment after 5 years. I was greatly affected by it and didn't expect that it would happen to me. All my emotions were mixed up, most of the time; I felt lonely, depressed, and in denial of the situation. My job performance was affected and I started drinking and going to late-night party/gimmick." - Ryan

"My daughter started living away from us as she becomes a college student. In this instance, it gives me pain to give my full support during those time that she's experiencing some academic challenges." - Nina "The recent event that really affected me was when my married life was set to trouble due to my deteriorating relationship with my husband. Because of my in-laws, I felt that we've been taken for granted by my husband. He dies not take my side. He made me feel that his parents are more important than us (me \& my children)." - Ellen

It is normal for women to re-evaluate themselves through their close relationships as a mother and wife. Thus, they don't perceive work or issues with colleagues as a challenge as compared to males who value their existence based on their jobs. ${ }^{3}$ Men are taught to give value to characteristics such as assertiveness, independence, achievement, and individuation while women are encouraged to be sensitive, attached, caring, and concerned. ${ }^{48}$
Here are sample statements to compare Richard and Emilia's narratives:

\section{Richard's story was related to work:}

"Being more sensitive with my feelings, specifically towards handling my emotions during work time. It is the time where we put so much effort and even extend hours to do other tasks in our jobs but still, we don't feel appreciated."

"There was an obvious disconnect when it came to my desire for learning which I got from my job. I felt that I wasn't able to address that desire. I need to learn more."

Whereas Emilia mentioned family relation more than work:

"I can relate it to my surge of emotions and increase in weight, disagreement with my daughter's decision to resign from her work overseas. Drastic change has caught me off-guard with little time to prepare."

"I felt that there is a misalignment with me and my husband. I think I see myself as a hard worker. I'm not saying that he's not but, during the weekend, I would do all the house shores and he would still be sleeping."

With these narratives, it was clear that both male and female Senior Executives have the same concerns and issues except in their perception about work and relationship. A woman's career timeline is not parallel to that of a man's. ${ }^{49}$ Women are interrupted by their pregnancy and motherhood. They also added that men are taught to value their work as it provides them the sense of identity as the provider of the family while women are confused with how to balance their career and being a mother and wife. Though, there are no gender differences when it comes to career-related psychological distress and that women encounter burdens at the workplace similar with men. ${ }^{50}$

\section{Conclusion}

From the researcher's thorough examination of the current scenario, exploration of the review of related literature, FGD and interview, the following findings emerged:

a. Due to the emerging future, Senior Executives become conscious of their apparent aging (19 of 41 [46\%]) and possible health problems (16 of $41[39 \%])$.

b. More than half of the Senior Executives are self-deliberating (37 of 41 [90\%]) and confused (23 of 41 [56\%]),

c. A number of female Senior Executives (11 of 18 [61\%]) are found to be more concerned about their relationship towards family and friends than males (7 of $23[30 \%]$ ).

Male and female Senior Executives have similar patterns of challenges such as:

A. Impermanence for health and aging issues

B. Individuality for self-deliberation and confusion

C. Interrelation for family and friends as well as concerns and issues with work/colleagues

With this analysis, it evidently shows that these Senior Executives are indeed going through tough times in their lives. Each of them has his/her own story to tell and they want some questions answered. They are indeed confused and they assess their lives by attempting to know on what's next for them. This phenomenological research only proves that previous studies such as those of Jung and Erikson 
are valid enough to conclude that midlife crisis exists. It cannot be generalized that crisis at midlife stage affects all midlifers but it could be assumed that there are midlifers who are enormously disturbed. Other individuals, on the other hand, experience crisis only at one point in midlife. Many or few, what matters is that there are individuals who are distressed because of this challenging life stage, who need to understand the circumstances and who need guidance which to aid them in their daily lives. Giving awareness is already provided by this phenomenological study and challenges are already identified among middle-aged Senior Executives. The only missing component is the intervention program which is the main purpose of this study.

\section{Acknowledgments}

We would like to express our sincere gratitude to our Almighty God, who gave us the wisdom and strength to accomplish this study. Everything was made possible because of his abundant grace and blessings.

We would also like to thank the member of the committee: Dr. Lucila Bance, Dr. Eugene Hontiveros, Dr. Rosalia Caballero, Dr. Clarissa Delariarte, and Dr. Karen Trinidad, for the continuous support, motivation, insightful comments and encouragement.

We would also like to show gratitude to our English Editor, Dr. Augusto Antonio Aguila, for his availability and continuous support in helping us come up with a must written research work.

Last but not the least, we would like to show appreciation to our families: our husbands and children for providing inspiration throughout the writing of this study.

Mary Jane Valero and Ma. Claudette Agnes.

\section{Conflicts of interest}

Author declare that there is no conflict of interest.

\section{References}

1. Lachman M. Mind the gap in the middle: A call to study midlife. Research inHuman Development. 2015;12:327-334.

2. Galeon GA. The work concerns of the faculty at midlife: A phenomenologicalcase study. International Journal of Sciences: Basic and Applied Research. 2015;5(2);71-79.

3. Shultz DP, Shultz SE. Theories of personality (11th ed.). BO, USA Cengage Learning. 2017.

4. Gross R, Kinnison N. Psychology of nurses and allied health professionals. NY, USA: Routledge. 2013.

5. Liu L, Rettenmaier A, Saving T. A rational choice theory of midlife crisis". Economics Bulletin. 2012;32(1):51-58.

6. Inkson K, Dries N, Arnold J. Understanding career. 2nd ed. California, USA:SAGE. 2015.

7. Robinson O. Development through adulthood: An integrative sourcebook. NY,USA: Palgrave Macmillan. 2013.

8. Hinde N. Anxiety levels peak in middle-aged people, nationwide study reveals. 2016.

9. Robinson J. The effects of stress on your body. 2017.

10. Anxiety and depression association of america. (n.d.). Stress. [Accessed 15th March 2017].

11. Cheng T, Powdthavee N, Oswald A. Longitudinal evidence for a midlife Nadir in human well-being: results from data sets. The Economic Journal. 2015;127(599);126-142.
12. Blanch flower D, Oswald A. Do modern humans suffer a psychological low in midlife? two approaches. 2017.

13. Chakravarthy B, Frumin E, Lotfipour S. Increasing suicide rates among middle-age persons and interventions to manage patients with psychiatric complaints. The Western Journal of Emergency Medicine. 2014;15(1);1113.

14. Sullivan EM, Annest JL, Luo F, et al. Suicide among adults aged 35-64 years - United States, 1999-2010. Morbidity and Mortality Weekly Report. 2013;62(17).

15. Brown M. Suicides peak in middle age. So why do we call it a young person's tragedy?. 2017.

16. Redaniel MT, Lebanan-Dalida MA, Gunnell, D. Suicide in the Philippines:time trend analysis (1974-2005) and literature review. BMC Public Health. 2011;11:536.

17. Feist J, Feist G, Roberts T. Theories of personality. 8th edn. NY, USA:McGraw-Hill Education. 2013.

18. Erford BT. An advanced lifespan odyssey for counseling professionals. BO, USA: Cengage Learning. 2017.

19. Levinson DJ. A conception of adult development. American Psychologist. 1986;41(1):3-13.

20. Berger KS. The developing person through the life span. 2nd ed. New York, NY: Worth Publishers. 2014.

21. Balswick JO, King PE, Reimer K S. The reciprocating self: Human development in theological perspective. 2nd ed. IL, USA: Inter Varsity. 2016.

22. Ewen RB. An introduction to theories of personality. 7th ed. NY, USA: Psychology Press, Taylor and Francis Group. 2014.

23. Staude, JR. The adult development of C.G. Jung: RLE Jung. NY, USA:Routledge. 2014

24. Lachman M, Teshale S, Agrigoroaei S. Midlife as a pivotal period in the life course: Balancing the growth and decline at the crossroads of youth and old age. International Journal of Behavioral Development. 2015;39(1):20-31.

25. Miller H. Jr. The sage encyclopedia of theory of psychology. CA, USA: SAGE. 2016.

26. Kelcourse FB. Human development and faith. 2nd ed. St. Louise, Missouri:Chalice. 2015.

27. Palk LC. An exploratory study of midlife transition in South Africa: In search of the midlife crisis. 2015.

28. Phillips S. Marriage and midlife crisis: a journey of challenge and transition. 2017

29. McLeod SA. Erik Erikson. [Accessed 17th October 2018]. 2018.

30. Malone J, Valliant GE, Rentz DM, et al. Midlife Eriksonian psychosocial development: Setting the stage for late-life cognitive and emotional health. Developmental Psychology. 2016:52(3);496-508.

31. Lachma ME, Weaver SL. The midlife development inventory (MIDI) Personality Scales: Scale construction and scoring. Technical report. Waltham, MA: Brandeis University, Department of Psychology. 1997.

32. Brooks C. The 10 most (and least) stressful jobs. Business News Daily Senior Writer. 2017

33. Khan AF, Akhtar A, Talib P. Modeling of midlife stress: an ISM approach. Global Journal of Management and Business Research: Administration and Management. 2014;14(7);28-42.

34. Cohen S, Williamson G. Perceived stress in a probability sample of the United States: The social psychology of health. CA, USA: SAGE. 1988. 
35. Zigmond AS, Snaith P. The hospital anxiety and depression scale. Acto Psychiatrrica Scandinavica. 1983;67:361-270.

36. Barker C, Pistrang N, Elliott R. Research methods in clinical psychology: an introduction for students and practitioners. 3rd ed. NY, USA: John Wiley \& Sons. 2015.

37. Freeman, EW. Depression in the menopause transition: risks in the changing hormone milieu as observed in the general population. Women's Midlife Health. 2015.

38. Zeltzer L, Kloda L. Hospital anxiety and depression scale. 2008.

39. Bocrean C, Dupret E. A validation study of the hospital anxiety and depression scale (HADS) in a large sample of french employees. $B M C$ Psychiatry. 2014;14:354.

40. Nowell L, Norris J, White D, et al. Thematic analysis: Striving to meet the trustworthiness criteria. International Journal of Qualitative Methods. 2017;16:1-13.

41. Strenger C. Paring down life to the essentials: an epicurean psychodynamics of midlife change. Psychoanalytic Psychology. 2009;26(3):246-258.

42. Santroc JW. Life-span development (16th ed.). NY, USA: McGraw-Hill Education. 2017.

43. Setiya K. The midlife crisis. philosopher's imprint. 2014;14 (31)
44. Plaisie I, De Bruijn JGM, de Graaf R, et al. The contribution of working conditions and social support to the onset of depressive and anxiety disorders among male and female employees. Social Science and Medicine. 2007;64;401-410.

45. Wade TD, Kendler KS. The relationship between social support and major depression: Cross-sectional, longitudinal, and genetic perspectives. The Journal of Nervous and Mental Disease. 2000;188:251-258.

46. Wirtz PH, von Känel R, Mohiyeddini C, et al. Low social support and poor emotional regulation are associated with increased stress hormone reactivity to mental stress in systemic hypertension. The Journal of Clinical Endocrinology and Metabolism. 2006;91:3857-3865.

47. Chernus LA. Intersubjectivity theory revisited: A 30-year retrospective. Psychoanalytic Social Work. 2017;24(2):163-170.

48. Capuzzi D, Stauffer MD. Human growth and development across the lifespan. Canada: John Wiley \& Sons. 2016.

49. Ornstein S, Isabella L. Age vs stage models of career attitudes of women: a partial replication and extension. Journal of Vocational Behavior. 1990;36:1-19.

50. Barnett RC, Brennan RT, Marshall NL. Gender and the relationship between parent role quality and psychological distress: a study of men and women in dual-earner couples. Journal of Family Issues. 1994;15(2):229252 